\title{
Simultaneous catalytic ozonation degradation of metronidazole and removal of heavy metal from aqueous solution using nano-magnesium hydroxide
}

Qi Sun, Guangcan Zhu, Jun Wu, Jian Lu \& Zhenhua Zhang

To cite this article: Qi Sun, Guangcan Zhu, Jun Wu, Jian Lu \& Zhenhua Zhang (2019):

Simultaneous catalytic ozonation degradation of metronidazole and removal of heavy metal from aqueous solution using nano-magnesium hydroxide, Environmental Technology, DOI: 10.1080/09593330.2019.1648560

To link to this article: https://doi.org/10.1080/09593330.2019.1648560

Published online: 08 Aug 2019.

Submit your article to this journal ¿

Џll Article views: 6

Q View related articles $\square$

View Crossmark data ¿ 


\title{
Simultaneous catalytic ozonation degradation of metronidazole and removal of heavy metal from aqueous solution using nano-magnesium hydroxide
}

\author{
Qi Sun ${ }^{a}$, Guangcan Zhu', Jun $\mathrm{Wu}^{\mathrm{b}}$, Jian $\mathrm{Lu}^{\mathrm{c}, \mathrm{d}}$ and Zhenhua Zhang ${ }^{\mathrm{b}}$ \\ ${ }^{a}$ School of Energy and Environment, Key Laboratory of Environmental Medicine Engineering of the Ministry of Education, Southeast University, \\ Nanjing, Jiangsu, People's Republic of China; 'School of Resources and Environmental Engineering, Ludong University, Yantai, Shandong, \\ People's Republic of China; 'CAS Key Laboratory of Coastal Environmental Processes and Ecological Remediation, Yantai Institute of Coastal

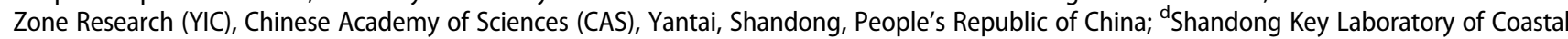 \\ Environmental Processes, YICCAS, Yantai, Shandong, People's Republic of China
}

ABSTRACT

Simultaneous removal of the antibiotics and heavy metals has attracted increasing attention since these contaminants are frequently detected in the aquatic environment. In this study, highly active nano- $\mathrm{Mg}(\mathrm{OH})_{2}$ was synthesized and firstly applied in catalytic ozonation system for simultaneous removal of metronidazole (MNZ) and heavy metal ions $\left(\mathrm{Cu}^{2+}\right.$ and $\left.\mathrm{Zn}^{2+}\right)$. The results showed that the synthesized $\mathrm{Mg}(\mathrm{OH})_{2}$ nanoparticles exhibited high efficiencies of removing both MNZ and heavy metal ions $\left(\mathrm{Cu}^{2+}\right.$ and $\left.\mathrm{Zn}^{2+}\right)$ in the catalytic ozonation process. Surprisingly, the removal efficiency of MNZ in the catalytic ozonation system with nano- $\mathrm{Mg}(\mathrm{OH})_{2}$ catalyst was improved in the presence of $\mathrm{Cu}^{2+}$ and $\mathrm{Zn}^{2+}$. Some parameters such as catalyst dosage, initial concentration of MNZ, initial concentration of heavy metal and reaction temperature could affect the simultaneous removal of MNZ and heavy metal ions $\left(\mathrm{Cu}^{2+}\right.$ and $\left.\mathrm{Zn}^{2+}\right)$. This study provides an innovative and effective method for the simultaneous removal of antibiotics and heavy metals from the aquatic environment.
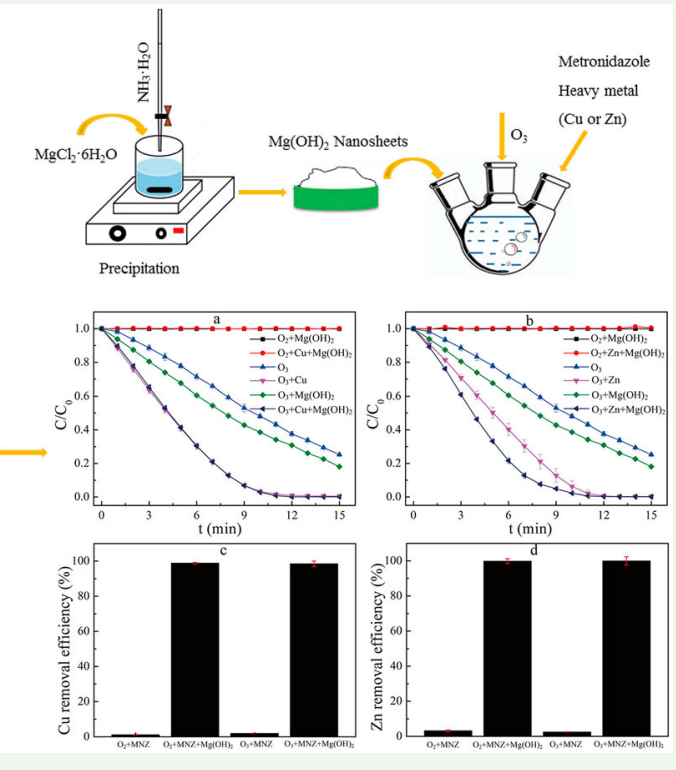

ARTICLE HISTORY

Received 18 March 2019

Accepted 19 July 2019

\section{KEYWORDS}

Nano-magnesium hydroxide: catalytic ozonation; simultaneous removal: metronidazole; heavy metals

\section{Introduction}

With the fast industrialization and urbanization, pharmaceuticals and their metabolites in the environment have induced important issues threating aquatic organisms, agricultural products and human health $[1,2]$. Antibiotics, an important class of pharmaceutical compounds, have been widely used for promoting growth and treating bacterial infections of humans and animals $[3,4]$. The used antibiotics constantly enter the aquatic environmental through human and animal excretion, the

CONTACT Guangcan Zhu gc-zhu@seu.edu.cn $\Theta$ School of Energy and Environment, Key Laboratory of Environmental Medicine Engineering of the Ministry of Education, Southeast University, Nanjing, Jiangsu 210096, People's Republic of China; Jun Wu wujunlisa@163.com E School of Resources and Environmental Engineering, Ludong University, Yantai, Shandong 264025, People's Republic of China

○ 2019 Informa UK Limited, trading as Taylor \& Francis Group 
discharged wastewater and sewage, treatment of unused or expired antibiotics, and other sources [4,5]. These antibiotics are frequently detected in the groundwater, drinking water, surface water and effluents of sewage treatment plants since they possess the high potential of resistance to degradation [6,7]. Therefore, the advanced oxidation processes (AOPs) such as photocatalysis [8], photoelectrocatalytic degradation [3], ozonation [9], photo-Fenton [10] and electro-Fenton $[10,11]$ technologies have been used to remove antibiotics. As an alternative, the catalytic ozonation process has been found to be very effective in eliminating refractory organic pollutants with short reaction time and high removal efficiency $[9,12]$. Heavy metal ions, kind of typical inorganic pollutants, are widely used in various industries and animal breeding, leading to high concentrations in the wastewater $[3,5,13]$. Heavy metals will pose potential risks to human health and ecosystems due to their high solubility, easy migration, high toxicity and persistence [14]. Thus, it is of crucial importance to develop effective strategies to control heavy metal pollution. Many techniques such as adsorption [15], photocatalysis [16], chemical precipitation [17], and ion exchange [18] have been used to remove heavy metal ions from aqueous environments.

Wastewater usually contains different kinds of contaminants such as organic pollutants and inorganic pollutants. In recent years, the combined pollution of heavy metal ions and antibiotics in aquatic systems has become an increasing concern in aqueous environments. Antibiotics can interact with heavy metal ions to produce complex substances which might possess stronger toxicity $[3,5]$. Therefore, it is necessary to establish an effective method to remove both antibiotics and heavy metals in aqueous environments.

Nanoscale magnesium hydroxide (nano- $\mathrm{Mg}(\mathrm{OH})_{2}$ ) as inorganic metal oxide is the low-cost, non-toxic and environment-friendly nanomaterial, showing excellent adsorption capacity for removing the heavy metal ions from the aqueous solution [15]. Moreover, nano- $\mathrm{Mg}(\mathrm{OH})_{2}$ is also used as the ozonation catalyst with a high catalytic performance for the degradation of antibiotics by forming highly reactive and non-selective hydroxyl radicals [1]. Rare reports are available on the simultaneous removal of antibiotics and heavy metal ions from aqueous solutions by catalytic ozonation using nano- $\mathrm{Mg}(\mathrm{OH})_{2}$ as a catalyst.

In this study, highly active nano- $\mathrm{Mg}(\mathrm{OH})_{2}$ was prepared and firstly used for simultaneous removal of antibiotics and heavy metal ions from aqueous solution in the catalytic ozonation process. Metronidazole (MNZ), one of the widely used nitroimidazole antibiotics, was chosen as representative compounds of antibiotics for removal study. Copper ion $\left(\mathrm{Cu}^{2+}\right)$ and zinc ion $\left(\mathrm{Zn}^{2+}\right)$ which widely exist in aqueous media $[3,14]$ were used as the representative heavy metal ions. The morphology and compositions of nano-Mg(OH $)_{2}$ before and after removal of antibiotics and heavy metals were characterized by SEM-EDS and XPS. In addition, the effect of various parameters including catalyst dosage, initial heavy metal concentration, initial antibiotic concentration and reaction temperature on the simultaneous removal of MNZ and heavy metals were evaluated. This technology has the potential for energy conservation compared to individually remove heavy metals and antibiotic.

\section{Materials and methods}

\subsection{Reagents}

MNZ (purity $>99 \%$ ) was provided by Shanghai Macklin Biochemical Co., Ltd. The analytical grade magnesium chloride $\left(\mathrm{MgCl}_{2} \cdot 6 \mathrm{H}_{2} \mathrm{O}\right)$, polyethylene glycol (PEG 400) and ammonium hydroxide $\left(\mathrm{NH}_{3} \cdot \mathrm{H}_{2} \mathrm{O}\right)$ used as the raw materials for synthesizing nano- $\mathrm{Mg}(\mathrm{OH})_{2}$ catalyst were obtained from Sinopharm Chemical Reagent Co. Ltd. (Shanghai, China). HPLC grade acetonitrile used for high performance liquid chromatography (HPLC) was purchased from Merck (Germany). The copper chloride dehydrate $\left(\mathrm{CuCl}_{2} \cdot 2 \mathrm{H}_{2} \mathrm{O}\right)$, zinc chloride $\left(\mathrm{ZnCl}_{2}\right)$ and sodium nitrite $\left(\mathrm{NaNO}_{2}\right)$ were all of analytical reagents. $\mathrm{NaNO}_{2}$ was used as a quencher. Distilled water was used throughout the whole experiment process.

\subsection{Preparation of nano- $\mathrm{Mg}(\mathrm{OH})_{2}$ catalyst}

Nano-Mg(OH $)_{2}$ was prepared according to the previous study [1]. Briefly, the $\mathrm{MgCl}_{2} \cdot 6 \mathrm{H}_{2} \mathrm{O}(10.165 \mathrm{~g})$ and PEG $400(10 \mathrm{~mL})$ were dissolved in the $100 \mathrm{~mL}$ distilled water, and then the mixture was placed in a $50^{\circ} \mathrm{C}$ constant temperature bath. The $8 \mathrm{~mL}$ ammonium hydroxide $\left(\mathrm{NH}_{3} \cdot \mathrm{H}_{2} \mathrm{O}\right)$ was added into the above solution through a dropping funnel. The mixture was stirred vigorously for $1.5 \mathrm{~h}$ at $50^{\circ} \mathrm{C}$, cooled down to room temperature, and aged at room temperature for another $1.5 \mathrm{~h}$. The obtained white precipitate was filtered and washed several times with distilled water and ethanol, and then dried at $60^{\circ} \mathrm{C}$ for $12 \mathrm{~h}$.

\subsection{Ozonation experiments}

The batch experiments were carried out in a $100 \mathrm{~mL}$ three-necked flask at $25 \pm 2{ }^{\circ} \mathrm{C}$. The high-purity oxygen was introduced into the ozone generator (Wohuan Co., Ltd.), and then the required mixture gas flow rate was adjusted by the rotor flowmeter and continuously 
pumped into the reaction solution. In each experiment, $100 \mathrm{~mL}$ aqueous solution containing $50 \mathrm{mg} \mathrm{L}^{-1} \mathrm{MNZ}$, a certain amount of heavy metal ion solution $\mathrm{CCu}^{2+}$ and $\mathrm{Zn}^{2+}$ ) and desired catalysts dosage was added to the flask. The solution was stirred by a magnetic stirrer (852 , Shuangjie, Shanghai) throughout the process to well mix the catalyst. During the experiment, the stirring speed was controlled at $500 \mathrm{r} / \mathrm{min}$. Sample with the volume of $5 \mathrm{~mL}$ was collected periodically over time and immediately quenched with $200 \mu \mathrm{L}$ sodium nitrite $\left(\mathrm{NaNO}_{2}\right)$ solution $(0.015 \mathrm{~mol} / \mathrm{L})$ in order to eliminate residual ozone, and then centrifuged at $12,000 \mathrm{rpm}$ for $6 \mathrm{~min}$ to collect the supernatant for further analysis. In order to consider the adsorption effect of nano-Mg $(\mathrm{OH})_{2}$ catalyst on MNZ and heavy metal ions $\left(\mathrm{Cu}^{2+}\right.$ and $\left.\mathrm{Zn}^{2+}\right)$, the ozone generator was turned off and the clean oxygen was introduced into the reaction system under the same experimental conditions. Each experiment was performed in triplicate.

In order to investigate the influence of catalyst dosage on the simultaneous removal of MNZ and heavy metals, the catalyst dosage was set as $0,0.15,0.3,0.6$, and $1.0 \mathrm{~g} \mathrm{~L}^{-1}$. Temperature was set as 15,25 and $35^{\circ} \mathrm{C}$ to evaluate the influence of reaction temperature on the simultaneous removal of MNZ and heavy metals. The

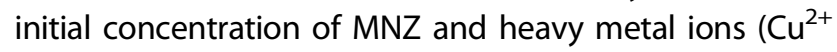
and $\mathrm{Zn}^{2+}$ ) were all set to $10,30,50,100,200$, and $500 \mathrm{mg} \mathrm{L}^{-1}$ to explore the effect of the initial concentration of target contaminant on removal efficiency of MNZ and heavy metals.

\subsection{Analytical methods}

The surface morphology and elemental composition of nano- $\mathrm{Mg}(\mathrm{OH})_{2}$ catalyst before and after reaction were analysed by Hitachi S-4800 field emission scanning electron microscopy (FESEM, Hitachi, Japan) combined with energy-dispersive $\mathrm{X}$-ray spectroscopy (EDS). X-ray photoelectron spectra (XPS) analysis was used to investigate the surface and metal oxidation state of nano- $\mathrm{Mg}(\mathrm{OH})_{2}$ catalyst before and after reaction by Thermo Scientific Escalab 250Xi X-ray photoelectron spectrometer with Al Ka X-ray excitation source operating at a vacuum pressure $\left(<10^{-7} \mathrm{~Pa}\right)$. The concentration of MNZ was analysed by an EX1600 high performance liquid chromatograph (HPLC, Wufeng Co., Shanghai, China) equipped with a Waters SunFire C18 reversed-phase column $(2.1 \times 150 \mathrm{~mm}, 3.5 \mu \mathrm{m})$ and a UV detector at a wavelength of $315 \mathrm{~nm}$. The mobile phase was $90 \%$ water and $10 \%$ acetonitrile with a flow rate of $0.2 \mathrm{~mL} \mathrm{~min}^{-1}$. In each analysis, $5 \mu \mathrm{L}$ samples were injected in an isocratic mode. The concentration of metal ions in the reaction process was determined by inductively coupled plasma optical emission spectrometer (ICP-OES, Optima DV7000, PerkinElmer, USA).

In this study, the pseudo-first-order kinetic model (Equation (1)) was used to describe the removal rate of MNZ:

$$
\ln C_{t}=\ln C_{0}-k t \text {, }
$$

where the $C_{O}\left(\mathrm{mg} \mathrm{L}^{-1}\right)$ and $C_{t}\left(\mathrm{mg} \mathrm{L}^{-1}\right)$ represents the initial concentration of MNZ and the concentration of MNZ at time $t$ ( $\mathrm{min})$, respectively; $k\left(\mathrm{~min}^{-1}\right)$ is the pseudo-first-order degradation rate constant.

\section{Results and discussion}

\subsection{Characterization of nano- $\mathrm{Mg}(\mathrm{OH})_{2}$ catalysts}

The SEM image of synthesized nano-Mg(OH $)_{2}$ catalyst (Figure 1(a)) indicated that the sample was composed of uniformly dispersed regular nano-plates with the size in the range of 50-300 $\mathrm{nm}$. Figure 1(c) and 1e exhibited the morphology of $\mathrm{Mg}(\mathrm{OH})_{2}$ after treating heavy metal $(\mathrm{Cu}$ and $\mathrm{Zn})$ and $\mathrm{MNZ}$. The $\mathrm{Mg}(\mathrm{OH})_{2}$ after reacting with MNZ and heavy metal still showed plate-like morphology with an average diameter of about $400 \mathrm{~nm}$. Obviously, the size of the final product after treating heavy metals and MNZ in solution was larger than that of $\mathrm{Mg}(\mathrm{OH})_{2}$ before use, which might be attributed to the adhesion of heavy metals and MNZ.

The chemical element composition of the catalyst was analysed using EDS technology, and the results were shown in Figure $1(b, d, f)$. As depicted in Figure $1(b)$, the magnesium and oxygen were the main elements existing in the prepared catalyst. Comparing the EDS spectrum before and after catalytic ozonation reaction, an obvious peak of $\mathrm{Cu}$ and $\mathrm{Zn}$ existed in the final product besides $\mathrm{Mg}$ and $\mathrm{O}$ elements to demonstrate that heavy metals ( $\mathrm{Cu}$ and $\mathrm{Zn}$ ) were adsorbed on the $\mathrm{Mg}(\mathrm{OH})_{2}$ after the catalytic ozonation.

The XPS analysis further confirmed the composition and elemental chemical state of the obtained materials. The survey spectra (Figure 2(a)) clearly indicated that the prominent peaks of synthesized $\mathrm{Mg}(\mathrm{OH})_{2}$ located at 1303.1, 531.1, 306.1, 88.1 and $49.1 \mathrm{eV}$ were assigned to $\mathrm{Mg}$ 1s, O 1s, Mg Auger, C 1s, Mg 2s and Mg 2p, respectively. Except for the $\mathrm{Mg}$ and $\mathrm{O}$ signal, the appearance of a small peak around 933 or $1021 \mathrm{eV}$ was also observed in the survey spectra, which further indicated the existence of $\mathrm{Cu}$ or $\mathrm{Zn}$ in the product after treating MNZ and heavy metals. These results were consistent with the EDS elemental analysis. From the high resolution XPS spectrum of $\mathrm{Cu} 2 \mathrm{p}$ (Figure 2(b)), it could be observed that the peaks centred in the region of $940-930 \mathrm{eV}$ and 960-950 eV corresponded to the $\mathrm{Cu} 2 \mathrm{p} 2 / 3$ and $\mathrm{Cu} 2 \mathrm{p} 1 /$ 

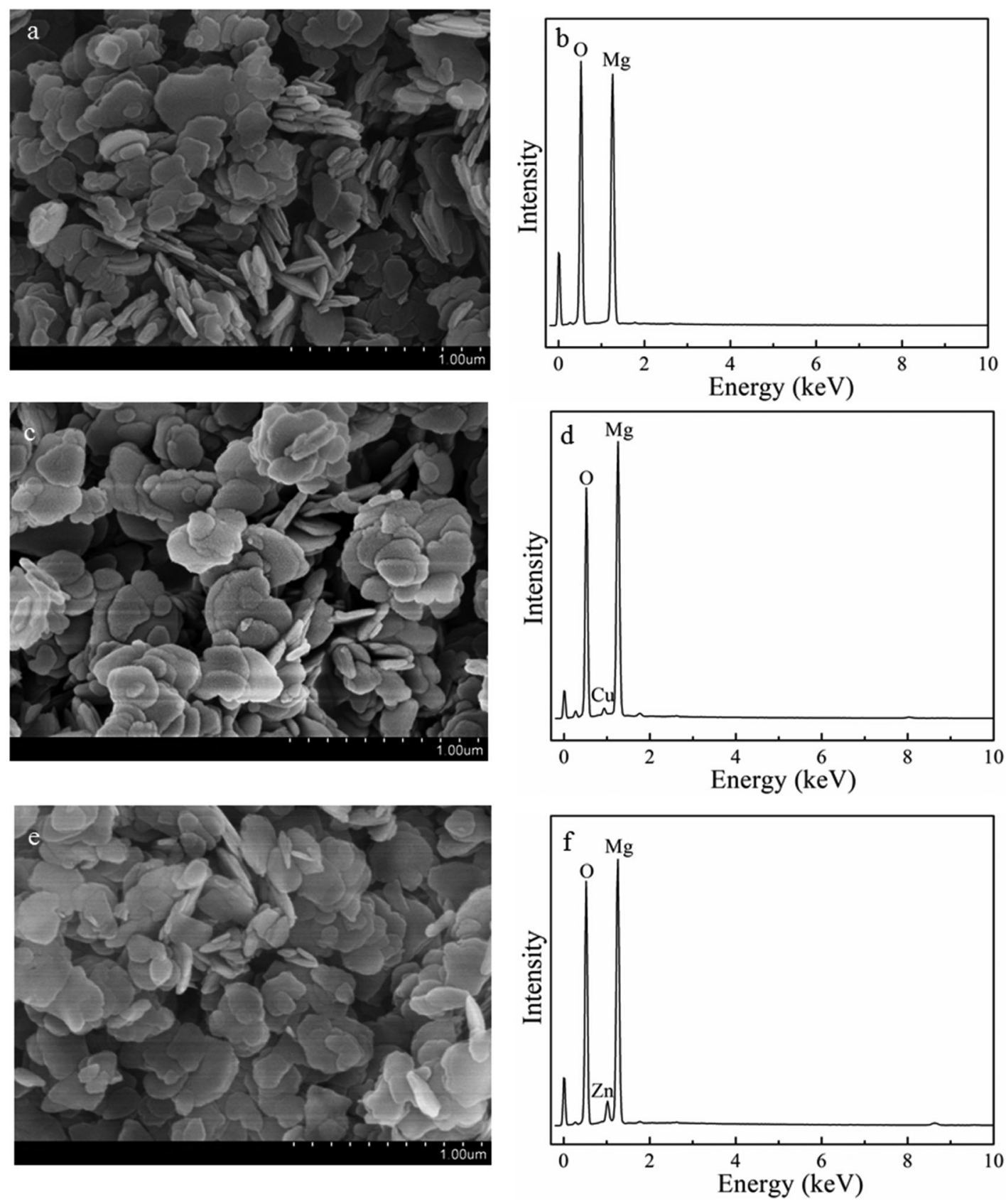

Figure 1. SEM image (a) and EDS spectra (b) of $\mathrm{Mg}(\mathrm{OH})_{2}$ before the reaction, SEM image (c) and EDS spectra $(\mathrm{d})$ of $\mathrm{Mg}(\mathrm{OH})_{2}$ after treating MNZ and $\mathrm{Cu}^{2+}$, SEM image (e) and EDS spectra $(\mathrm{f})$ of $\mathrm{Mg}(\mathrm{OH})_{2}$ after treating $\mathrm{MNZ}$ and $\mathrm{Zn}^{2+}$.

2 , respectively [5]. Herein, the peaks of $\mathrm{Cu} 2 \mathrm{p} 3 / 2$ spectra were split into two components with binding energies of 932.6 and $933.0 \mathrm{eV}$, which could be attributed to $\mathrm{Cu}(0)$ and $\mathrm{Cu}(\mathrm{II})$, respectively $[5,19]$. The satellite structure was observed at high binding energies of 944.5 and $940.8 \mathrm{eV}$ due to multiple divisions in the final state of $2 p^{5} 3 d^{9}$, which was directly related to the presence of $\mathrm{Cu}^{2+}$ species [20]. According to high resolution, $\mathrm{Zn} 2 p$ XPS spectra (Figure 2(c)), the peaks at 1022 and $1045 \mathrm{eV}$ should be assigned to the binding energy of the $Z n 2 p 2 / 3$ and Zn 2p1/2 level, respectively. The XPS results also further demonstrated that heavy metals were adsorbed on $\mathrm{Mg}(\mathrm{OH})_{2}$ after treating $\mathrm{MNZ}$ and heavy metals.

\subsection{Simultaneous removal of MNZ and heavy metals by various systems}

The simultaneous removal of MNZ and heavy metals ( $\mathrm{Cu}$ and $\mathrm{Zn}$ ) by catalytic ozonation process with the presence of nano- $\mathrm{Mg}(\mathrm{OH})_{2}$ catalyst was investigated (Figure 3). The efficiency of single ozonation in the removal of MNZ could only reach $51.8 \%$ with the reaction of $10 \mathrm{~min}$. The separate addition of heavy metals ( $\mathrm{Cu}$ and 

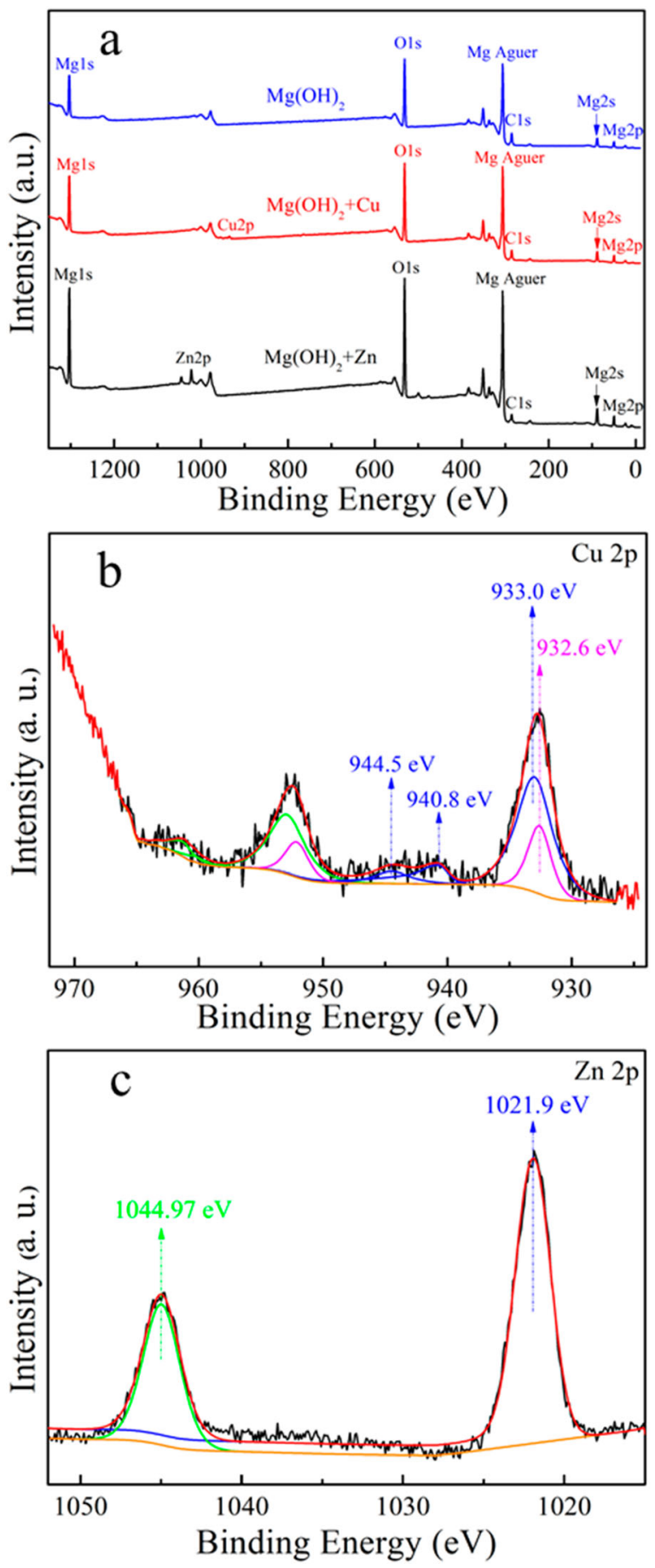

Figure 2. X-ray photoelectron spectroscopy (XPS) investigation of the $\mathrm{Mg}(\mathrm{OH})_{2}$ before and after treating $\mathrm{MNZ}$ and heavy metals, survey scan (a), $\mathrm{Cu} 2 \mathrm{p}$ of $\mathrm{Mg}(\mathrm{OH})_{2}$ after treating MNZ and $\mathrm{Cu}^{2+}$ (b) and $\mathrm{Zn} 2 \mathrm{p}$ of $\mathrm{Mg}(\mathrm{OH})_{2}$ after treating MNZ and $\mathrm{Zn}^{2+}(\mathrm{c})$.

$\mathrm{Zn})$ and nano-Mg(OH $)_{2}$ into the ozonation system caused an enhancement of the MNZ removal in different levels. When $\mathrm{Cu}, \mathrm{Zn}$ and nano- $\mathrm{Mg}(\mathrm{OH})_{2}$ were separately added to the ozonation system, the removal efficiency of MNZ reached $96.8 \%, 93.8 \%$ and $61.4 \%$ within $10 \mathrm{~min}$, respectively. The removal efficiency of MNZ reached the maximum when the heavy metals $\mathrm{Cu}$ or $\mathrm{Zn}$ and $\mathrm{Mg}$ $(\mathrm{OH})_{2}$ existed in the solution. This might be caused by the strong chelating capability of heavy metal and antibiotic [5]. The heavy metal and antibiotic, partially adsorbed at different sites of catalyst, could be chelated in the solution by forming complex species with higher sorption affinity $[5,14]$. A similar phenomenon was also observed by the other study [5]. In addition, the results of adsorption experiments showed that the MNZ adsorption onto $\mathrm{Mg}(\mathrm{OH})_{2}$ catalyst was just around $1 \%$ within $15 \mathrm{~min}$, indicating that the increase of MNZ removal efficiency was mainly caused by degradation rather than adsorption.

The removal data of MNZ were fitted with the pseudofirst-order kinetic model (Figure $3(c, d)$ ). The reaction rate constant of MNZ increased by 39.5\%, 313.7\% and $222.5 \%$ with $\mathrm{Mg}(\mathrm{OH})_{2}, \mathrm{Cu}$ and $\mathrm{Zn}$ added into the single ozonation system, respectively. However, the removal rate constant of MNZ increased from $0.089 \mathrm{~min}^{-1}$ to $0.267 \mathrm{~min}^{-1}$ or $0.311 \mathrm{~min}^{-1}$ when $\mathrm{Mg}(\mathrm{OH})_{2}$ was added into the ozonation system in the presence of heavy metals $\mathrm{Cu}$ or $\mathrm{Zn}$. This result confirmed good catalytic performance of $\mathrm{Mg}(\mathrm{OH})_{2}$ on the ozonation of MNZ and promotion on the removal of heavy metals during the ozonation process of MNZ.

The removal efficiency of $\mathrm{Cu}$ and $\mathrm{Zn}$ in the absence of $\mathrm{Mg}(\mathrm{OH})_{2}$ was very low to be almost neglected (Figure 3 $(\mathrm{e}, \mathrm{f}))$. However, $50 \mathrm{mg} \mathrm{L}^{-1}$ of $\mathrm{Cu}$ and $\mathrm{Zn}$ were almost completely removed in the presence of nano- $\mathrm{Mg}(\mathrm{OH})_{2}$ after $15 \mathrm{~min}$ both in the oxygen or ozone reaction system. This result indicated that the adsorption of $\mathrm{Mg}(\mathrm{OH})_{2}$ could explain the removal of heavy metals. Simultaneous removal of heavy metals and MNZ in the catalytic ozonation process was achieved successfully. The nano-Mg $(\mathrm{OH})_{2}$ could significantly promote simultaneous removal of heavy metals and MNZ in the ozonation process. Moreover, the catalytic performance of nano-Mg(OH $)_{2}$ was dramatically enhanced in the presence of heavy metals.

\subsection{Effect of catalyst dosage}

In order to study the dose-dependent effect on the removal of MNZ and heavy metals, the reaction was run with different dosages of $\mathrm{Mg}(\mathrm{OH})_{2}$ ranging between 0 and $1.0 \mathrm{~g} / \mathrm{L}$ (Figure 4). In the mixed system containing MNZ and $\mathrm{Cu}$, the removal efficiency of MNZ increased slightly with the increase of catalyst dosage (Figure 4(a)). The removal rate constant of MNZ only increased by $1.0 \%$ as the catalyst concentration reached $1.0 \mathrm{~g} \mathrm{~L}^{-1}$. The removal efficiency of $\mathrm{Cu}$ reached the maximum of $98.4 \%$ within 15 min when the catalyst dosage increased to $0.6 \mathrm{~g} \mathrm{~L}^{-1}$ and then limited improvements were observed with further increased catalyst concentration to $1.0 \mathrm{~g} \mathrm{~L}^{-1}$ (Figure 4(c)). 

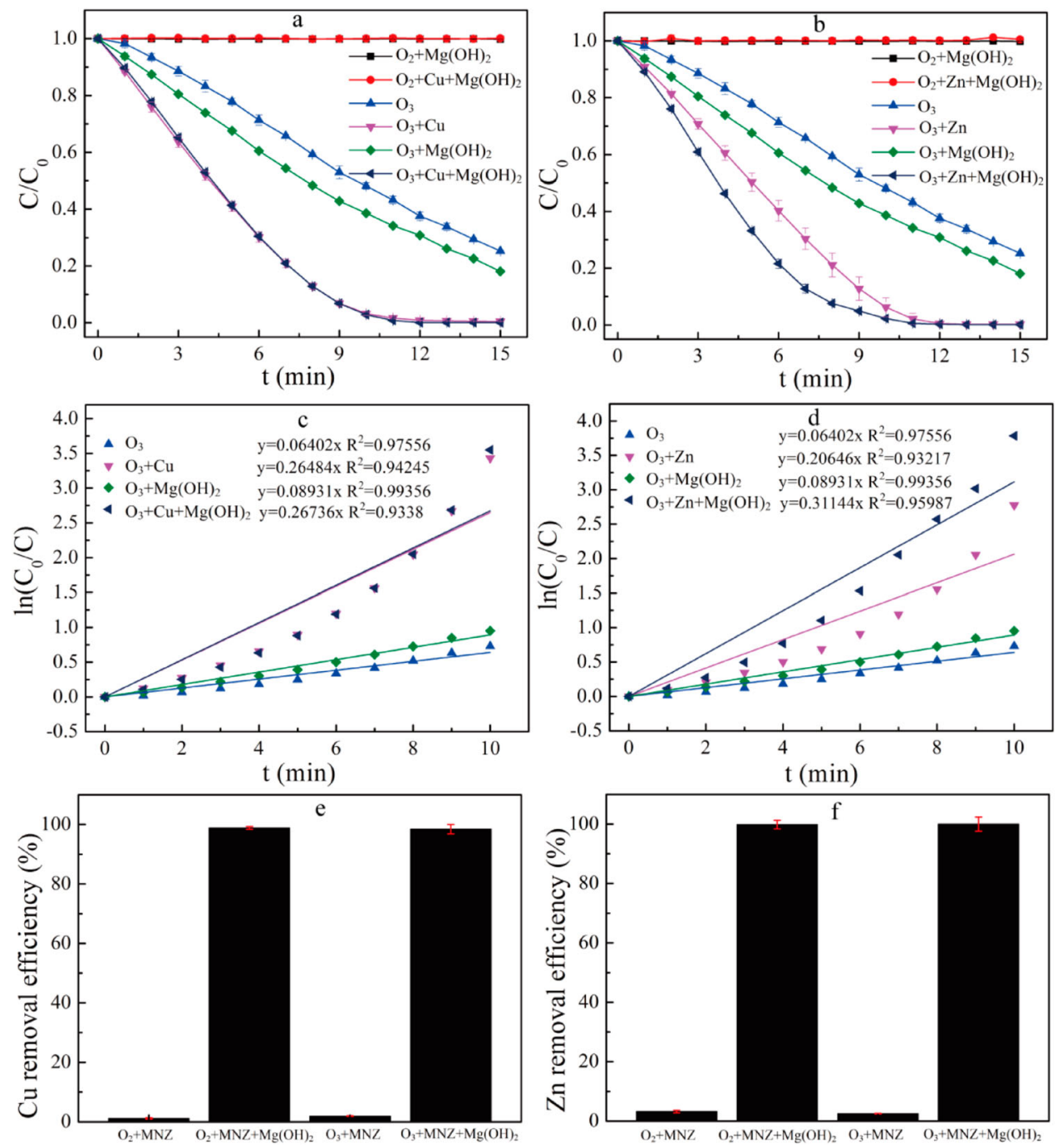

Figure 3. Simultaneous removal of MNZ and heavy metals by various systems. MNZ removal (a), kinetic fitting (c) and Cu removal (e) in the mixed system containing MNZ and Cu. MNZ removal (b), kinetic fitting (d) and Zn removal (f) in the mixed system containing MNZ and Zn.

In the mixed system containing MNZ and Zn, the catalytic effect was obvious and the MNZ removal rate constant increased by $45.2 \%$ as nano- $\mathrm{Mg}(\mathrm{OH})_{2}$ with a concentration of $0.15 \mathrm{~g} \mathrm{~L}^{-1}$ was added into the system (Figure 4(b)). The removal efficiency of MNZ reached the maximum capacity with the catalyst dosage of $0.6 \mathrm{~g} \mathrm{~L}^{-1}$ and then the removal efficiency gradually decreased with further increased catalyst dosage. The variation trend of removing $\mathrm{Zn}$ from the aqueous solution was similar to that of removing $\mathrm{Cu}$ (Figure 4(d)). In generally, the removal efficiency of MNZ and heavy metals ( $\mathrm{Cu}$ and $Z n$ ) firstly increased and then decreased with the increase of catalyst dosage in the above-mentioned two mixed systems. The results were consistent with previous studies reporting the simultaneous removal of hexavalent chromium and dye using zero-valent iron or zero-valent iron composite $[21,22]$. This was attributed to the available actives sites [22,23]. The active sites and surface areas increased as the increase in catalyst dosage to improve the reaction rate. However, the removal efficiency of MNZ decreased with the amount of catalyst exceeding a certain value due to the limited amount of ozone in the system [24]. Thus, $0.6 \mathrm{~g} \mathrm{~L}^{-1}$ was chosen as the catalyst dosage in the following experiments by considering the maximum removal efficiency of MNZ and heavy metal.

\subsection{Effect of the initial concentration of heavy metal}

The influence of initial concentration of heavy metals (10, $30,50,100,200$, and $500 \mathrm{mg} / \mathrm{L}$ ) on the simultaneous removal of $M N Z$ and heavy metals ( $\mathrm{Cu}$ and $\mathrm{Zn}$ ) from a mixed solution containing MNZ and $\mathrm{Cu}$ or $\mathrm{Zn}$ was evaluated (Figure 5). MNZ removal rates increased by $35.5 \%$ and $28.0 \%$ with the initial concentration of $\mathrm{Cu}$ and $\mathrm{Zn}$ 

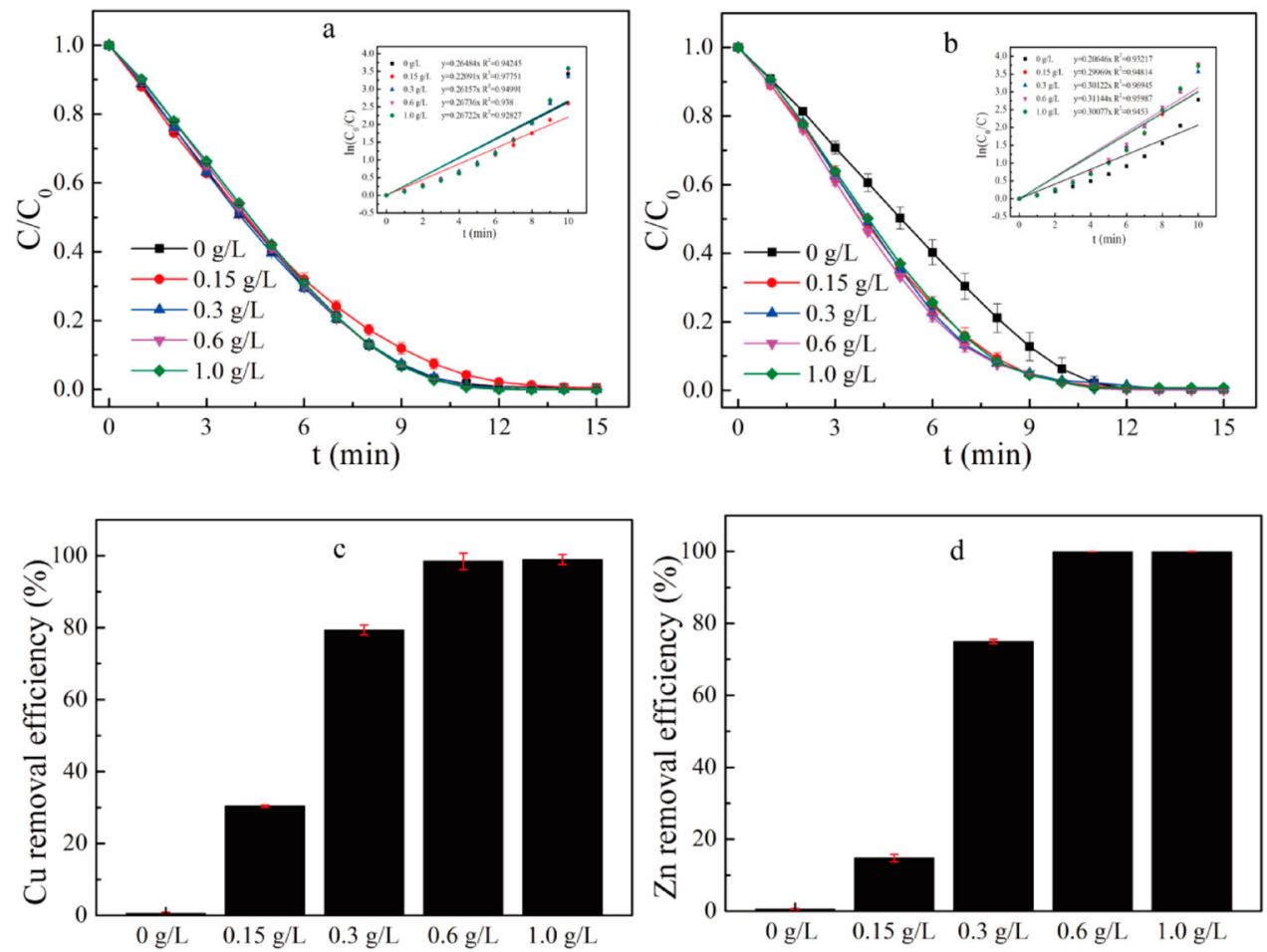

Figure 4. Effect of catalyst dosage on simultaneous removal of MNZ and heavy metal. MNZ and Cu removal within 15 min in the mixed system containing MNZ and $\mathrm{Cu}(\mathrm{a}, \mathrm{c})$, and MNZ and Zn removal within 15 min in the mixed system containing MNZ and Zn (b, d). Inset: Pseudo-first-order kinetic fitting for MNZ removal at different catalyst dosage.
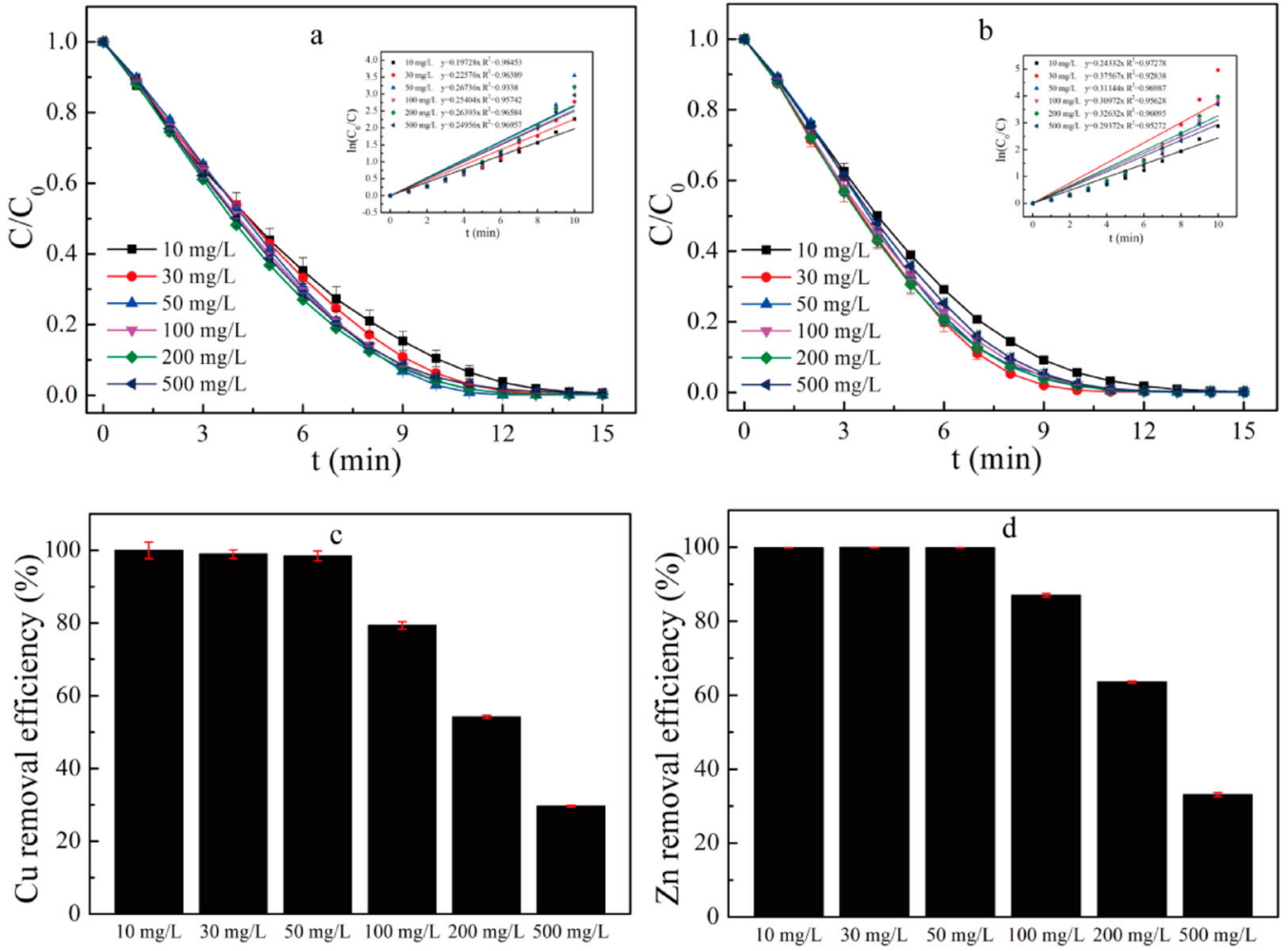

Figure 5. Effect of initial heavy metal concentration on simultaneous removal of MNZ and heavy metal. MNZ and Cu removal within 15 min in the mixed system containing MNZ and $\mathrm{Cu}(\mathrm{a}, \mathrm{c})$, and MNZ and Zn removal within $15 \mathrm{~min}$ in the mixed system containing MNZ and $\mathrm{Zn}(\mathrm{b}, \mathrm{d})$. Inset: Pseudo-first-order kinetic fitting for MNZ removal at different initial heavy metal concentration. 

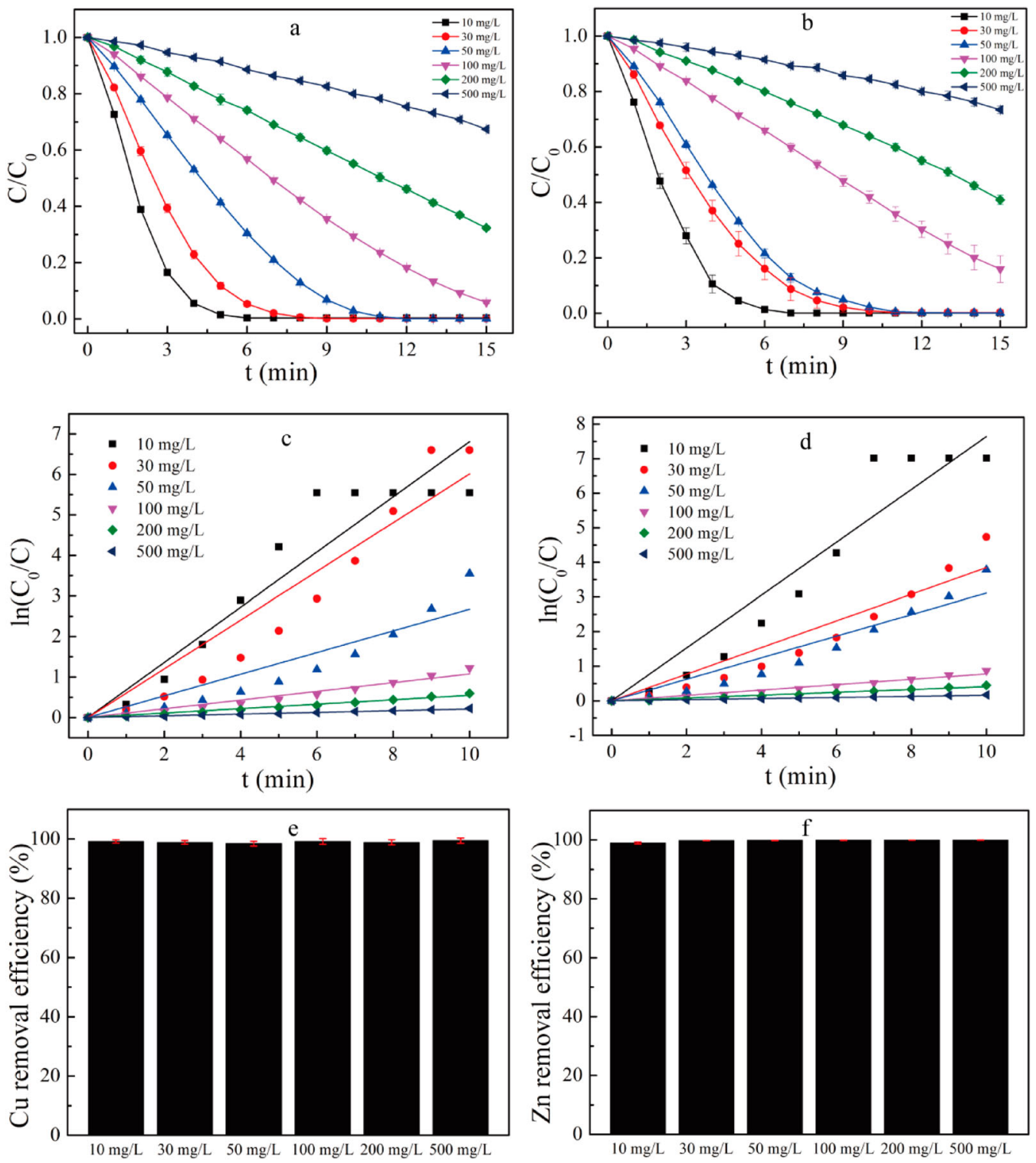

Figure 6. Effect of initial MNZ concentration on simultaneous removal of MNZ and heavy metal. MNZ removal (a), kinetic fitting (c) and Cu removal (e) in the mixed system containing MNZ and Cu. MNZ removal (b), kinetic fitting (d) and Zn removal (f) in the mixed system containing MNZ and Zn.

increasing from 10 to $50 \mathrm{mg} / \mathrm{L}$, respectively (Figure $5(\mathrm{a}, \mathrm{b})$ ). Moreover, no obvious increase in MNZ removal rate was observed as the $\mathrm{Cu}$ and $\mathrm{Zn}$ concentration was further increased to $500 \mathrm{mg} / \mathrm{L}$, which might be explained by the fact that most of the active sites of the catalyst were occupied by heavy metals $[16,25]$. The removal efficiency of $\mathrm{Cu}$ and $Z n$ reduced from $99.9 \%$ and $99.8 \%$ to $29.7 \%$ and $33.1 \%$ with the initial concentration of $\mathrm{Cu}$ and $\mathrm{Zn}$ increased from $10 \mathrm{mg} \mathrm{L}^{-1}$ to $500 \mathrm{mg} \mathrm{L}^{-1}$, which might be caused by the limited active sites of the composites [26].

\subsection{Effect of the initial concentration of MNZ}

The removal efficiency of MNZ decreased in the mixed solution containing MNZ and heavy metals with an increase in the initial concentration of MNZ (Figure 6 (a)-(d)). In the mixed solution containing $\mathrm{Cu}$ and MNZ, the MNZ removal rate constant decreased by $96.9 \%$ from 0.681 to $0.021 \mathrm{~min}^{-1}$ as the MNZ initial concentration increased from 10 to $500 \mathrm{mg} \mathrm{L}^{-1}$. A similar variation pattern of MNZ removal was observed in the mixed solution containing $\mathrm{Zn}$ and MNZ. The concentration of organic intermediates might increase as MNZ concentration increased, which would result in the formation of more available ozone for further removal of intermediates $[1,9,27]$. In addition, excessive antibiotics and degradation intermediates could be adsorbed on the catalyst surface with the increase of the initial pollutant concentrations, which inhibited the surface reaction and led to lower removal efficiency $[26,28,29]$. No 

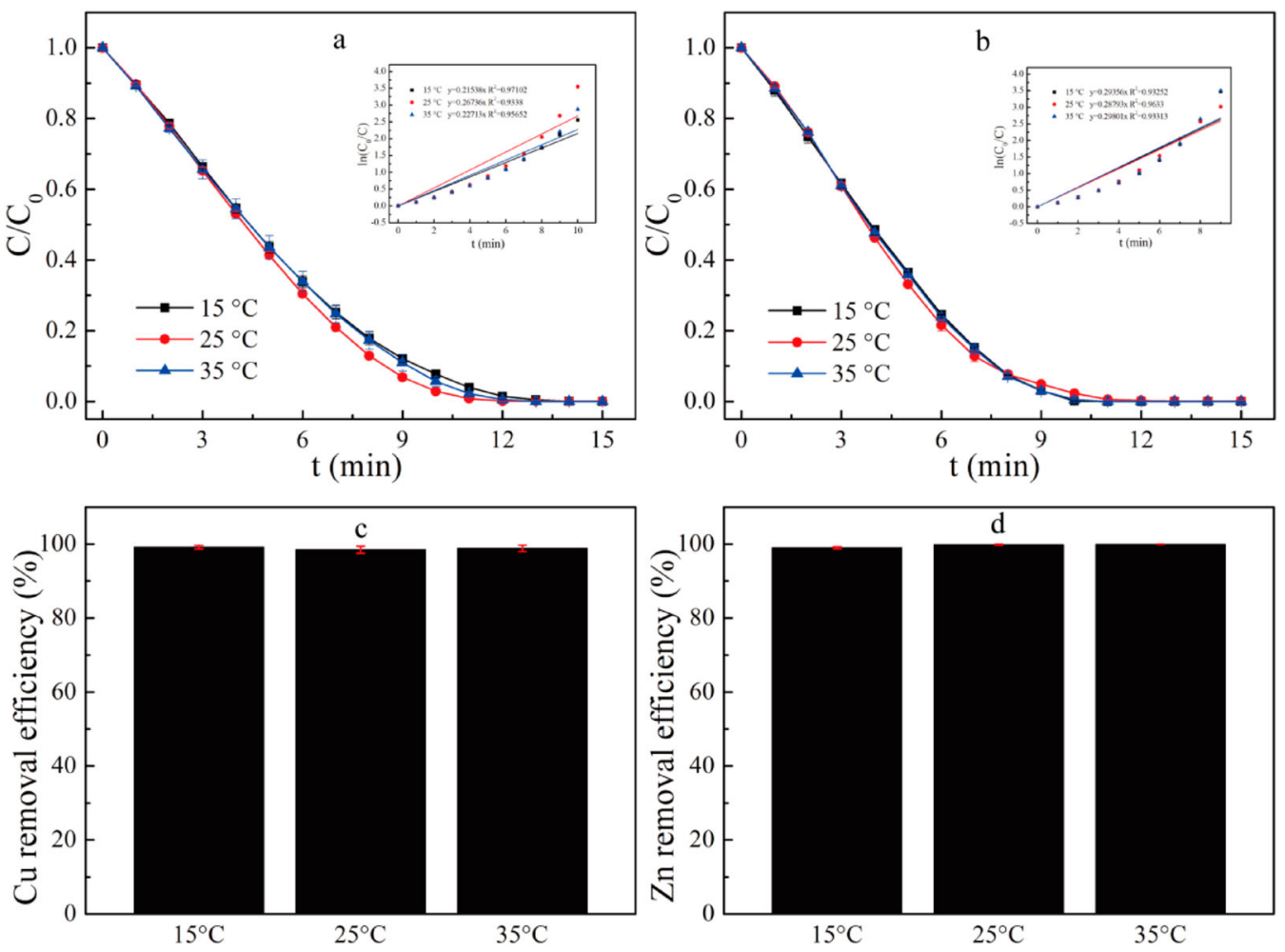

Figure 7. Effect of reaction temperature on simultaneous removal of MNZ and heavy metal. MNZ and Cu removal within 15 min in the mixed system containing MNZ and $\mathrm{Cu}(\mathrm{a}, \mathrm{c})$, and MNZ and Zn removal within 15 min in the mixed system containing MNZ and Zn (b, d). Inset: Pseudo-first-order kinetic fitting for MNZ removal at different reaction temperature.

significant changes in $\mathrm{Cu}$ and $\mathrm{Zn}$ removal efficiency were observed, regardless of increasing or decreasing the concentration of MNZ (Figure $6(\mathrm{e}, \mathrm{f})$ ), similar to the previous report [21].

\subsection{Effect of reaction temperature}

The effect of reaction temperature on the removal of MNZ and heavy metals ( $\mathrm{Cu}$ and $\mathrm{Zn}$ ) by catalytic ozonation process was shown in Figure 7. Figure $7(a, b)$ showed that the reaction temperature had little influence on the removal efficiency of MNZ no matter whether $\mathrm{Cu}$ or $\mathrm{Zn}$ existed in the catalytic ozonation process. In the presence of Cu during the catalytic ozonation, the removal rate constant of MNZ slightly increased from 0.215 to $0.267 \mathrm{~min}^{-1}$ as the reaction temperature increased from $15^{\circ} \mathrm{C}$ to $25^{\circ} \mathrm{C}$. However, the reaction rate constant of MNZ slightly decreased by $15.0 \%$ when the reaction temperature continued to increase from $25^{\circ} \mathrm{C}$ to $35^{\circ} \mathrm{C}$ (Figure $7(\mathrm{a})$ ). The same phenomenon was observed by the other scientists when they investigated the effect of reaction temperature on bisphenolA ozonation in the presence of $\mathrm{a}-\mathrm{MnO}_{2} /$ graphene composites [24]. In the presence of $\mathrm{Zn}$ during the catalytic ozonation, the reaction rate constant of MNZ only increased by $1.5 \%$ with the reaction temperature increasing from $15^{\circ} \mathrm{C}$ to $35^{\circ} \mathrm{C}$ (Figure $7(\mathrm{~b})$ ). The above phenomenon might be caused by the balance between the reaction rate of ozonation and solubility of ozone. On the one hand, the chemical reaction rate and mass transfer were improved with the increased reaction temperature, which directly accelerated the MNZ removal efficiency [30,31]. On the other hand, the solubility of ozone in aqueous solution would decrease when the reaction temperature increased, which reduced the ozone concentration in the aqueous solution to suppress the MNZ removal [12,24]. The combined result of these two opposite processes caused the effect of reaction temperature on the catalytic ozonation of MNZ in the presence of heavy metals. Figure 7(c, d) showed that the reaction temperature had very limited impact on the removal of $\mathrm{Cu}$ and $\mathrm{Zn}$ in the catalytic ozonation process. The removal efficiency of $\mathrm{Cu}$ and $\mathrm{Zn}$ did not change much no matter whether the reaction temperature was increased or decreased.

\section{Conclusion}

Nanoscale magnesium hydroxide (nano- $\mathrm{Mg}(\mathrm{OH})_{2}$ ) were successfully prepared and firstly applied to simultaneously remove $\mathrm{MNZ}$ and heavy metal ions $\mathrm{CCu}^{2+}$ and $\left.\mathrm{Zn}^{2+}\right)$ in water through catalytic ozonation process. 
The prepared nano- $\mathrm{Mg}(\mathrm{OH})_{2}$ exhibited higher efficiencies for removing MNZ and heavy metals. The multiple factors such as catalyst dosage, initial concentration of $M N Z$, initial concentration of heavy metal and reaction temperature had an important influence on the simultaneous removal of MNZ and heavy metals. Increase in the catalyst dosage within a certain range could improve the removal efficiency of MNZ and heavy metals. Increase in the initial concentration of heavy metals led to the decrease in the removal efficiency of heavy metals while the removal efficiency of MNZ did not significantly change. Increase in the initial MNZ concentration caused the sharp decrease in the removal efficiency of MNZ while an increase in the reaction temperature led to the increase in the removal efficiency of MNZ within a limited range. No significant changes in the removal efficiency of $\mathrm{Cu}$ and $\mathrm{Zn}$ were observed as the initial MNZ concentration and reaction temperature varied. This work offers an available approach for the simultaneous removal of antibiotics and heavy metals from aquatic environments.

\section{Disclosure statement}

No potential conflict of interest was reported by the authors.

\section{Funding}

This work was funded by the National Natural Science Foundation of China [grant numbers 41877131 and 51578132], Taishan Scholar Program of Shandong Province [grant number tsqn201812116], One Hundred Talents Program of Chinese Academy of Sciences [grant number Y629041021], Thousand Talents Plan of Qinghai Province [grant number Y740171071], and Two-Hundred Talents Plan of Yantai [grant number Y739011021].

\section{References}

[1] Sun Q, Lu J, Wu J, et al. Catalytic ozonation of sulfonamide, fluoroquinolone, and tetracycline antibiotics using nanomagnesium hydroxide from natural bischofite. Water Air Soil Pollut. 2019;230:55. doi:10.1007/s11270-019-4108-y.

[2] Yin R, Guo W, Du J, et al. Heteroatoms doped graphene for catalytic ozonation of sulfamethoxazole by metal-free catalysis: performances and mechanisms. Chem Eng J. 2017;317:632-639. doi:10.1016/j.cej.2017.01.038.

[3] Liu L, Li R, Liu Y, et al. Simultaneous degradation of ofloxacin and recovery of $\mathrm{Cu}$ (II) by photoelectrocatalysis with highly ordered $\mathrm{TiO}_{2}$ nanotubes. J Hazard Mater. 2016;308:264-275. doi:10.1016/j.jhazmat.2016.01.046.

[4] Lu J, Wu J, Zhang C, et al. Occurrence, distribution, and ecological-health risks of selected antibiotics in coastal waters along the coastline of China. Sci Total Environ. 2018;644:1469-1476. doi:10.1016/j.scitotenv.2018.07.096.
[5] Zhang Z, Liu H, Wu L, et al. Preparation of amino-Fe (III) functionalized mesoporous silica for synergistic adsorption of tetracycline and copper. Chemosphere. 2015;138:625632. doi:10.1016/j.chemosphere.2015.07.014.

[6] Carvalho IT, Santos L. Antibiotics in the aquatic environments: a review of the European scenario. Environ Int. 2016;94:736-757. doi:10.1016/j.envint.2016.06.025.

[7] Liu X, Lu S, Guo W, et al. Antibiotics in the aquatic environments: a review of lakes, China. Sci Total Environ. 2018;627:1195-1208. doi:10.1016/j.scitotenv.2018.01.271.

[8] Khataee A, Kıranşan M, Karaca S, et al. Photocatalytic ozonation of metronidazole by synthesized zinc oxide nanoparticles immobilized on montmorillonite. J Taiwan Inst Chem E. 2017;74:196-204. doi:10.1016/j.jtice.2017.02.014.

[9] Bai Z, Yang Q, Wang J. Catalytic ozonation of sulfamethazine using $\mathrm{Ce}_{0.1} \mathrm{Fe}_{0.9} \mathrm{OOH}$ as catalyst: mineralization and catalytic mechanisms. Chem Eng J. 2016;300:169-176. doi:10.1016/j.cej.2016.04.129.

[10] Liu X, Zhou Y, Zhang J, et al. Insight into electro-Fenton and photo-Fenton for the degradation of antibiotics: mechanism study and research gaps. Chem Eng J. 2018;347:379-397. doi:10.1016/j.cej.2018.04.142.

[11] Liu X, Yang D, Zhou Y, et al. Electrocatalytic properties of $\mathrm{N}$-doped graphite felt in electro-Fenton process and degradation mechanism of levofloxacin. Chemosphere. 2017;182:306-315. doi:10.1016/j.chemosphere.2017.05. 035.

[12] Huang R, Lan B, Chen Z, et al. Catalytic ozonation of $p$ chlorobenzoic acid over MCM-41 and Fe loaded MCM41. Chem Eng J. 2012;180:19-24. doi:10.1016/j.cej.2011. 10.086.

[13] Chen A, Zeng G, Chen G, et al. Novel thiourea-modified magnetic ion-imprinted chitosan/ $/ \mathrm{TiO}_{2}$ composite for simultaneous removal of cadmium and 2,4-dichlorophenol. Chem Eng J. 2012;191:85-94. doi:10.1016/j.cej.2012.02. 071.

[14] Kyzas GZ, Siafaka PI, Pavlidou EG, et al. Synthesis and adsorption application of succinyl-grafted chitosan for the simultaneous removal of zinc and cationic dye from binary hazardous mixtures. Chem Eng J. 2015;259:438448. doi:10.1016/j.cej.2014.08.019.

[15] Liu M, Wang $Y$, Chen $\mathrm{L}$, et al. $\mathrm{Mg}(\mathrm{OH})_{2}$ supported nanoscale zero valent iron enhancing the removal of $\mathrm{Pb}$ (II) from aqueous solution. ACS Appl Mater Inter. 2015;7 (15):7961-7969. doi:10.1021/am509184e.

[16] Deng Y, Tang L, Zeng G, et al. Insight into highly efficient simultaneous photocatalytic removal of $\mathrm{Cr}(\mathrm{VI})$ and 2,4diclorophenol under visible light irradiation by phosphorus doped porous ultrathin $\mathrm{g}-\mathrm{C}_{3} \mathrm{~N}_{4}$ nanosheets from aqueous media: performance and reaction mechanism. Appl Catal B-Environ. 2017;203:343-354. doi:10.1016/j. apcatb.2016.10.046.

[17] Sheikholeslami R, Bright J. Silica and metals removal by pretreatment to prevent fouling of reverse osmosis membranes. Desalination. 2002;143(3):255-267. doi:10.1016/ S0011-9164(02)00264-3.

[18] Lee IH, Kuan YC, Chern JM. Factorial experimental design for recovering heavy metals from sludge with ionexchange resin. J Hazard Mater. 2006;138(3):549-559. doi:10.1016/j.jhazmat.2006.05.090.

[19] Wu L, Wang H, Lan H, et al. Adsorption of Cu(II)-EDTA chelates on tri-ammonium-functionalized mesoporous silica 
from aqueous solution. Sep Purif Technol. 2013;117 (1):118-123. doi:10.1016/j.seppur.2013.06.016.

[20] Zhao X, Guo L, Zhang B, et al. Photoelectrocatalytic oxidation of $\mathrm{Cu}^{\text {II-EDTA }}$ at the $\mathrm{TiO}_{2}$ electrode and simultaneous recovery of $\mathrm{Cu}^{\text {Il }}$ by electrodeposition. Environ Sci Technol. 2013;47(9):4480-4488. doi:10.1021/es3046982.

[21] Fu F, Han W, Tang B, et al. Insights into environmental remediation of heavy metal and organic pollutants: simultaneous removal of hexavalent chromium and dye from wastewater by zero-valent iron with ligand-enhanced reactivity. Chem Eng J. 2013;232:534-540. doi:10.1016/j. cej.2013.08.014.

[22] Kim SA, Kamala-Kannan S, Oh SG, et al. Simultaneous removal of chromium ( $\mathrm{VI})$ and reactive Black 5 using zeolite supported nano-scale zero-valent iron composite. Environ Earth Sci. 2016;75(5):447. doi:10.1007/s12665015-4855-z.

[23] Li X, Chen W, Ma L, et al. Industrial wastewater advanced treatment via catalytic ozonation with an Fe-based catalyst. Chemosphere. 2018;195:336-343. doi:10.1016/j. chemosphere.2017.12.080.

[24] Li G, Lu Y, Lu C, et al. Efficient catalytic ozonation of bisphenol-A over reduced grapheme oxide modified sea urchin-like $\mathrm{a}-\mathrm{MnO}_{2}$ architectures. J Hazard Mater. 2015;294:201-208. doi:10.1016/j.jhazmat.2015.03.045.

[25] Cai Y, Li C, Wu D, et al. Highly active MgO nanoparticles for simultaneous bacterial inactivation and heavy metal removal from aqueous solution. Chem Eng J. 2017;312:158-166. doi:10.1016/j.cej.2016.11.134.

[26] Abdollahi B, Shakeri A, Aber S, et al. Simultaneous photodegradation of acid orange 7 and removal of $\mathrm{Pb}^{2+}$ from polluted water using reusable clinoptilolite- $\mathrm{TiO}_{2}$ nanocomposite. Res Chem Intermediat. 2018;44(3):15051521. doi:10.1007/s11164-017-3181-3.

[27] Lü X, Zhang Q, Yang W, et al. Catalytic ozonation of 2, 4dichlorophenoxyacetic acid over novel Fe-Ni/AC. RSC Adv. 2015;5(14):10537-10545. doi:10.1039/C4RA11610K.

[28] Rao AN, Sivasankar B, Sadasivam V. Kinetic study on the photocatalytic degradation of salicylic acid using $\mathrm{ZnO}$ catalyst. J Hazard Mater. 2009;166(2-3):1357-1361.

[29] Ren Y, Zhang H, An H, et al. Catalytic ozonation of di-nbutyl phthalate degradation using manganese ferrite/ reduced graphene oxide nanofiber as catalyst in the water. J Colloid Interf Sci. 2018;526:347-355. doi:10. 1016/j.jcis.2018.04.073.

[30] Pi Y, Feng J, Song M, et al. Degradation potential of ofloxacin and its resulting transformation products during Fenton oxidation process. Chinese Sci Bull. 2014;59(21):2618-2624. doi:10.1007/s11434-0140293-7.

[31] Lan B, Huang R, Li L, et al. Catalytic ozonation of $p$-chlorobenzoic acid in aqueous solution using Fe-MCM-41 as catalyst. Chem Eng J. 2013;219:346-354. doi:10.1016/j. cej.2012.12.083 